\title{
Data Compression for Video-Conferencing using Half tone and Wavelet Transform
}

\author{
Dr. H.B.Kekre \\ Sr. Professor, Computer \\ Engineering, NMIMS University, \\ Mumbai-400056, India
}

\author{
Sanjay R. Sange \\ Assistant Professor, Information \\ Technology, NMIMS University, \\ Mumbai-400056, India
}

\author{
Dr. Tanuja K. Sarode \\ Associate Professor, Computer \\ Engineering, \\ TSEC, Mumbai University \\ Mumbai, India
}

\begin{abstract}
Overhead of data transmission over internet is increasing exponentially every day. Optimization of natural bandwidth is the basic motive by compressing image data to the maximum extend. For the same objective, combination of lossy half tone and lossless Wavelet Transform techniques is proposed so as to obtain low-bit rate video data transmission. Decimal values of bitmapped image are to be converted into either 1 or 0 in half toning process that incur pictorial loss and gives 8:1 compression ratio (CR) irrespective of image. Wavelet Transform is applied on half tone image for higher compression for various levels. An experimental result shows the higher CR, minimum Mean Square Error (MSE). Ten sample images of different people captured by Nikon camera are used for experimentation. All images are bitmap (.BMP) 512 X 512 in size. The proposed technique can be used for video conferencing, storage of movies and CCTV footage etc.
\end{abstract}

Keywords-Half tone; Low-Bit rate; video data compression; Wavelet Tranform; Bandwidth optimization; Structural Similarity Index Measure (SSIM).

\section{INTRODUCTION}

From last two decades Wavelet Transform has found enormous application in different areas like speech, computer graphics, signal, image processing and in medical field for DNA, ECG, protein, blood pressure, and heart rate analysis. Wavelet Transform overcomes the limitations of Fourier Transform as it cannot detect local properties as in [1]. Hybrid Wavelet Transform using any two orthogonal transform can be used for higher image data compression with minimum loss using a set of complimentary wavelets, where comparison of DCT, DHT, DWT and Kekre transform is explained as in [2]. The combination of Wavelet Transform with Modified-RunLength- Coding (MRLC) along with new quantization technique is proposed for ECG data compression. This proposed method improves data compression by $13 \%$ as in [3].

Generation of Wavelet Transform from any orthogonal transforms by contraction and translation infinite set of functions can be generated. Experimental results of original image with reconstructed image using orthogonal transforms Walsh and DCT with respect to their Wavelets are compared. Walsh Wavelet and DCT Wavelet results are better than Walsh and DCT as in [4].

Wavelet Transform for high resolution satellite imageries with lifting scheme is proposed that reduces computational time and resources with appreciable results as in [5].
Considering main three factors of high embedding capacity, imperceptibility and robustness effective stenography is explained with Walsh Wavelet and DCT Wavelet proven that are prone to filtering, noise, cropping and compression of an image as in [6]. Spikes at different frequencies and amplitude using Wavelet Transform for Neural data compression from different channels are found to reconstruct unique signature and relate it some activities as in [7]. Various orthogonal Wavelet transforms of Walsh, Cosine, Hartley, Kekre are used for image data compression and proved better results as compared to respective normal forms. $70 \%$ to $90 \%$ is compressed by removing low energy coefficients in their respective Wavelet forms as in [8].

Section II explains about the half tone method and various half tone operators, Section III explains the Hybrid Algorithm of Half tone and Wavelet Transform, Section IV explains about experimental results and discussion. In section $\mathrm{V}$ paper conclusion and future scope is explained.

\section{HALF TONING METHOD}

\section{A. Neighbourhood Processing}

Half toning is the process in which intensity and pattern of dot varies to simulate different shades. Half tone dots are produced by superimposing mask over the image. Half toning is the error diffusion process that results into noisy image. Half toning templates shown in fig.1a to fig.1d are used to convert continuous tone image into half tone image. These templates are rotated on continues tone image as neighborhood processing.

For the same objective of high image data compression and low-bit-rate data transmission to optimize bandwidth for video conferencing, other techniques are used as hybrid technique with half tone technique. Half toning is the lossy technique and gives 8:1 CR. Two-fold hybrid techniques are used for higher compression ratio with half tone. Half tone with Kekre's Fast Codebook Generation (KFCG) vector quantization technique is presented by Kekre et al as in [9]. Lossy half tone with lossless Huffman coding technique is presented as in [10]. Lossy half tone with lossless Run-Length-Encoding technique is presented as in [11]. Importance of red plane from time complexity point of view is explained as in [12]. For reconstruction of image from half tone image Inverse half toning algorithm as in [13] is described. Some other half toning operators are proposed with performance analysis as in [14]. 


\begin{tabular}{|c|c|c|}
\hline $\mathbf{0}$ & $\mathbf{0}$ & $\mathbf{0}$ \\
\hline $\mathbf{0}$ & $\underline{\mathbf{x}}$ & 7 \\
\hline 3 & $\mathbf{5}$ & $\mathbf{1}$ \\
\hline
\end{tabular}

Fig. 1a: Floyd-Steinberg

\begin{tabular}{|c|c|c|c|c|}
\hline $\mathbf{0}$ & $\mathbf{0}$ & $\mathbf{0}$ & $\mathbf{0}$ & $\mathbf{0}$ \\
\hline $\mathbf{0}$ & $\mathbf{0}$ & $\mathbf{0}$ & $\mathbf{0}$ & $\mathbf{0}$ \\
\hline $\mathbf{0}$ & $\mathbf{0}$ & $\underline{\mathbf{X}}$ & $\mathbf{7}$ & $\mathbf{5}$ \\
\hline $\mathbf{3}$ & $\mathbf{5}$ & $\mathbf{7}$ & $\mathbf{5}$ & $\mathbf{3}$ \\
\hline $\mathbf{1}$ & $\mathbf{3}$ & $\mathbf{5}$ & $\mathbf{3}$ & $\mathbf{1}$ \\
\hline
\end{tabular}

Fig. 1c.: Jarvis

\begin{tabular}{|c|c|c|}
\hline $\mathbf{0}$ & $\mathbf{0}$ & $\mathbf{0}$ \\
\hline $\mathbf{0}$ & $\underline{\mathbf{X}}$ & $\mathbf{1}$ \\
\hline $\mathbf{0}$ & $\mathbf{1}$ & $\mathbf{3}$ \\
\hline
\end{tabular}

Fig. 1b. Small

\begin{tabular}{|c|c|c|c|c|}
\hline 0 & 0 & 0 & 0 & 0 \\
\hline 0 & 0 & 0 & 0 & 0 \\
\hline 0 & 0 & $\underline{x}$ & 1 & 9 \\
\hline 23 & 7 & 5 & 3 & 11 \\
\hline 21 & 19 & 17 & 15 & 13 \\
\hline
\end{tabular}

Fig. 1d.: South-East

Figure 1. Half tone operators: Fig.1a is Floyd-Steinberg half tone operator, Fig.1b is Small half tone operator, Fig.1c is Jarvis half tone operator, Fig.1d is South-East half tone operator

\section{B. Quantization}

As shown fig. 2 color image is split into three primary R-GB planes and it posses gray levels from 0-255, representing each pixel by 8-bit. After half tone technique, quantization process is used to convert gray level into bi-level with loss as either 0 or 1 as in [13].

\section{HyBRID HALF TONE WiTH WAVELET AlgORITHM}

As shown in fig.2, on each plane of half tone image Haar Wavelet transform is applied. Fig.3 shows the working principle of Wavelet transform.

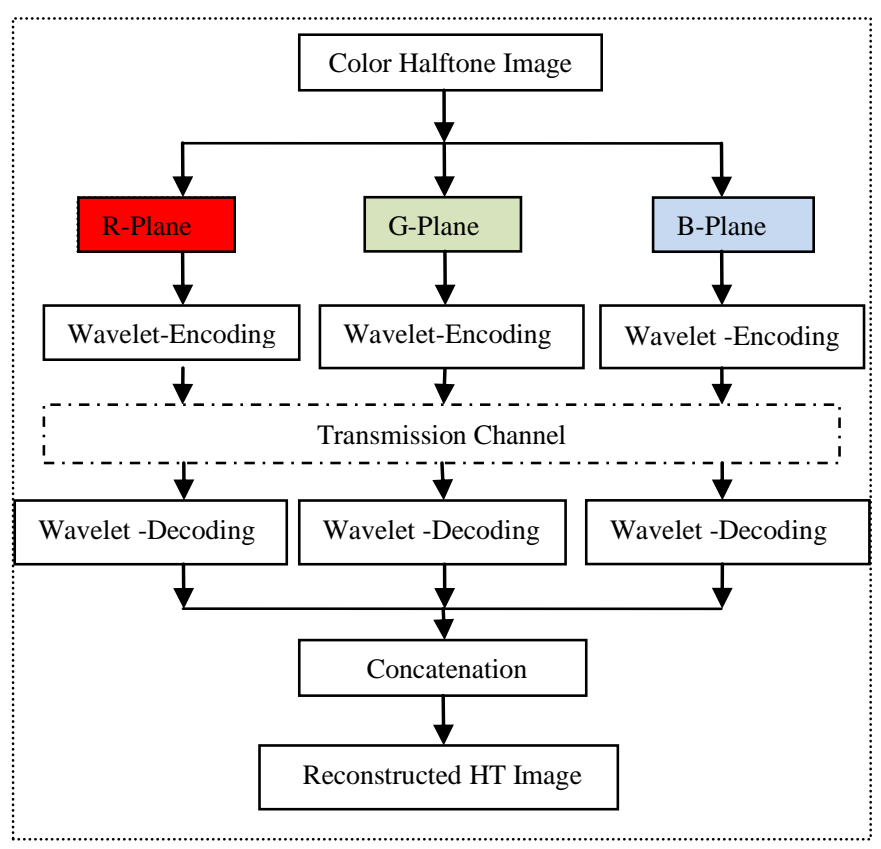

Figure 2. Block diagram of Half tone-Wavelet Transform

\section{A. Algorithm}

- Wavelet transform is applied on binary half tone image of size 512-by-512.

- In Wavelet transform alternate row and column is eliminated so as to reduce the overall NXN size of an image as is represented in fig. 3 and sample result is shown in fig. 4 . $b$

$$
\mathrm{L} i=\mathrm{N} / 2^{i}
$$

Where $i=1,2 \ldots \mathrm{n}$

- Wavelet transform is applied on half tone image plane till to the desired level of compression. At each level of compression Wavelet transform extract features at different frequencies and location.

- Wavelet transform encoded data in its highest compressed form can be used for transmission on channel.

- At the receiving end inverse Wavelet transform is applied to decode image data so as to obtain half tone image.

- Inverse half toning algorithm is applied with concatenation of all the half tone planes to reconstruct of an image.

\section{B. Compression Ratio $(C R)$}

In first iteration of Wavelet transform image size of 512-by512 in half tone form is converted into 256-by-256 as level-1 and referred as L1. At L1 Wavelet transform compresses data $50 \%$ to that of half tone image data as shown in fig. 3. Eq. (1) shows the decomposition of NXN size image into desired level Li. The Wavelet Transform is applied on low-low frequency component of $\mathrm{L} 1$, for further compression of $50 \%$ data is called as L2 and image size becomes 128-by-128 and henceforth L3 and L4 is achieved. The CR of original image to inverse image at L1 is 32 . In the same way, L2 compresses original image data 128 times, L3 compresses 512 times and L4 compresses 2048 times.

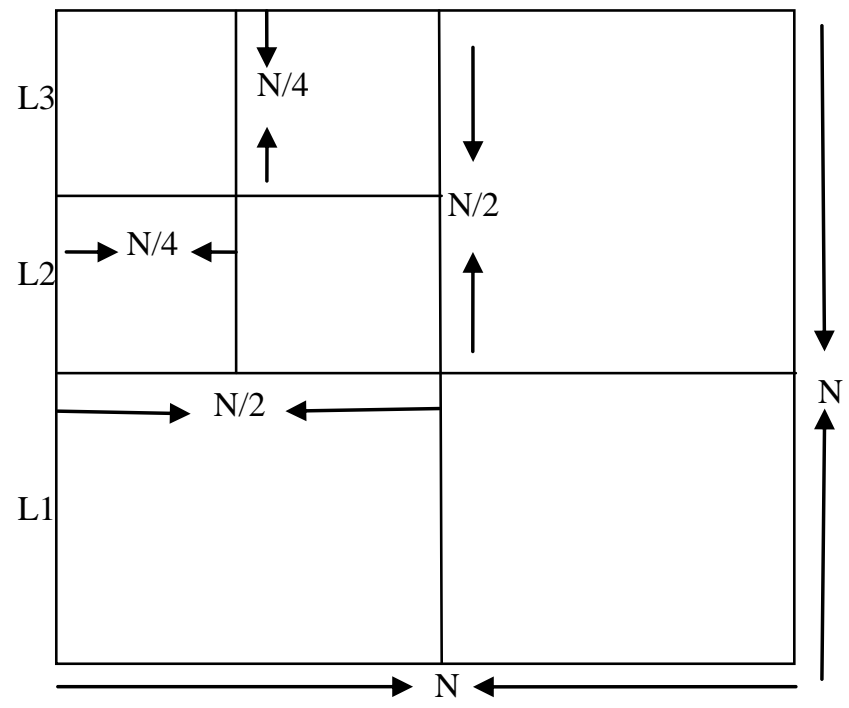

Figure 3. Wavelet Transform Pyramid 


\section{RESUlts AND Discussion}

Combination of Half tone with Wavelet Transform is used to achieve higher $\mathrm{CR}$ on different ten 512-by-512 in size bitmapped images, for low bit-rate image data compression in Video-Conferencing. Mean-Square-Error (MSE) and Structural Similarity Index Measure (SSIM) are used between original image and inverse image.

Table-I, III, V and Table-VII shows the MSE between original images and inverse image for different half tone operators at L1, L2, L3 and L4. As well as Table-II, IV, VI and Table-VIII shows the SSIM between original image and inverse images for different half tone operators at L1, L2, L3 and L4. Fig. 5, 7, 9 and 11 shows the graphical representation of MSE between original images and inverse image for different half tone operators at L1, L2, L3 and L4. As well as fig. $6,8,10$ and 12 shows the SSIM between original image and inverse images for different half tone operators at L1, L2, L3 and L4.

Fig. 13 shows the reconstructed images from different half tone operators and Wavelet Transform at levels from L1 to L4. Reconstructed image quality of Small operator is almost same to that of standard Floyd-Steinberg and Jarvis operators. As well as it gives same MSE and SSIM with reduced computational complexity [11].

Whereas South-East operator gives higher MSE and negligible poor in image quality as compared to standard operators. Fig. 13 shows the MSE increases and image quality decreases from L1 to L4. As shown in fig. 3, in each level only Low-Low frequency component is used to take inverse Wavelet transform. Remaining Low-High, High-Low and High-High components are considered as matrix of zeros of the same size in the respective level.

TABLE I. MSE- BETWEEN INVERSE AND ORIGINAL IMAGE USING DIFFERENT HALF TONE OPERATORS WAVELET TRANSFORM AT-L1

\begin{tabular}{|c|c|c|c|c|c|}
\hline S.N. & Image & Flyod & Jarvis & Small & $\begin{array}{c}\text { South- } \\
\text { East }\end{array}$ \\
\hline 1 & Aditi & 117.8627 & 215.8853 & 249.986 & 360.656 \\
\hline 2 & KekreHB & 318.1064 & 264.8021 & 391.9745 & 447.651 \\
\hline 3 & Sanjay & 285.8108 & 377.4874 & 398.578 & 621.227 \\
\hline 4 & Anita & 263.2586 & 452.0141 & 506.7903 & 903.042 \\
\hline 5 & Tandle & 142.0714 & 342.3254 & 389.9147 & 777.652 \\
\hline 6 & Pallavi & 130.8618 & 187.4659 & 171.0308 & 633.804 \\
\hline 7 & More & 172.1179 & 297.9908 & 316.0038 & 625.25 \\
\hline 8 & Shruti & 108.5584 & 177.0217 & 173.92 & 646.386 \\
\hline 9 & Ravi & 302.4952 & 224.187 & 287.0564 & 625.001 \\
\hline 10 & Ajay & 214.7108 & 195.7814 & 275.4807 & 577.054 \\
\hline & Average & 205.5854 & 273.49611 & 316.07352 & 621.772 \\
\hline
\end{tabular}

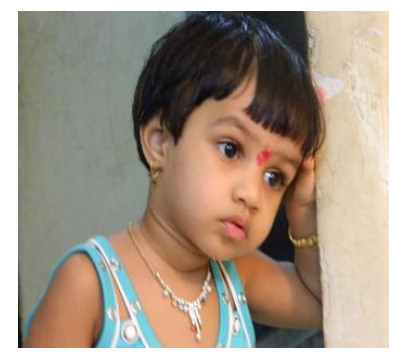

Figure 4. (a).Original image: Aditi

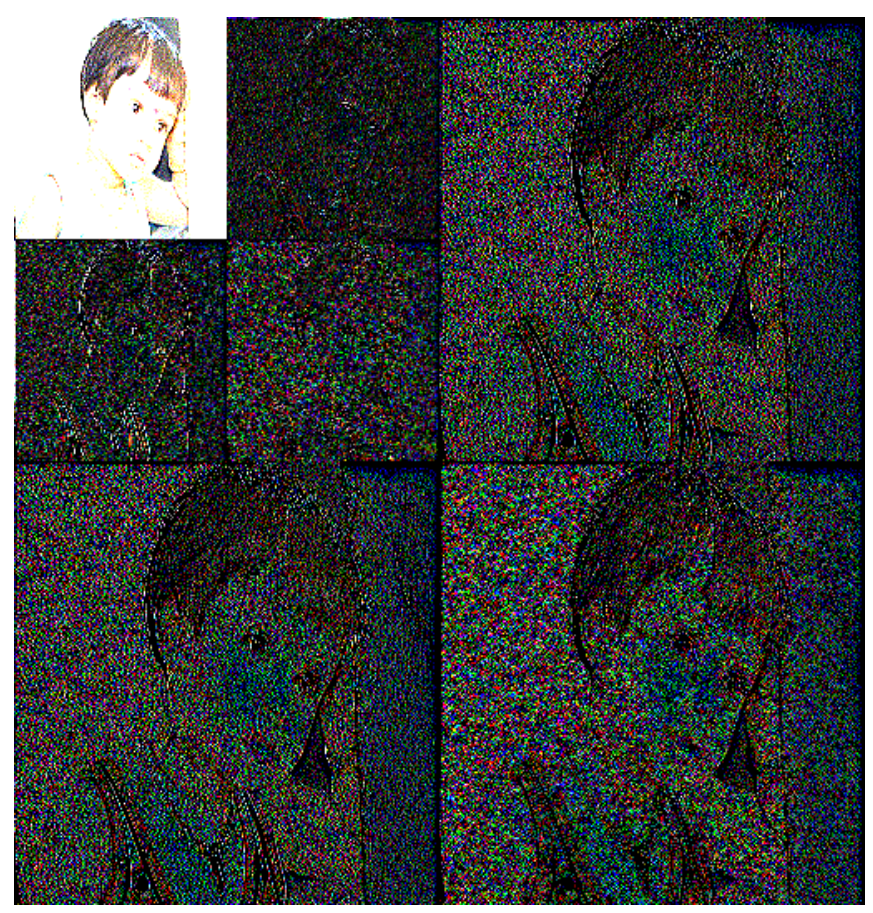

Figure 4.

(b). Aditi: Wavelet Transform (L3) image using Jarvis half tone

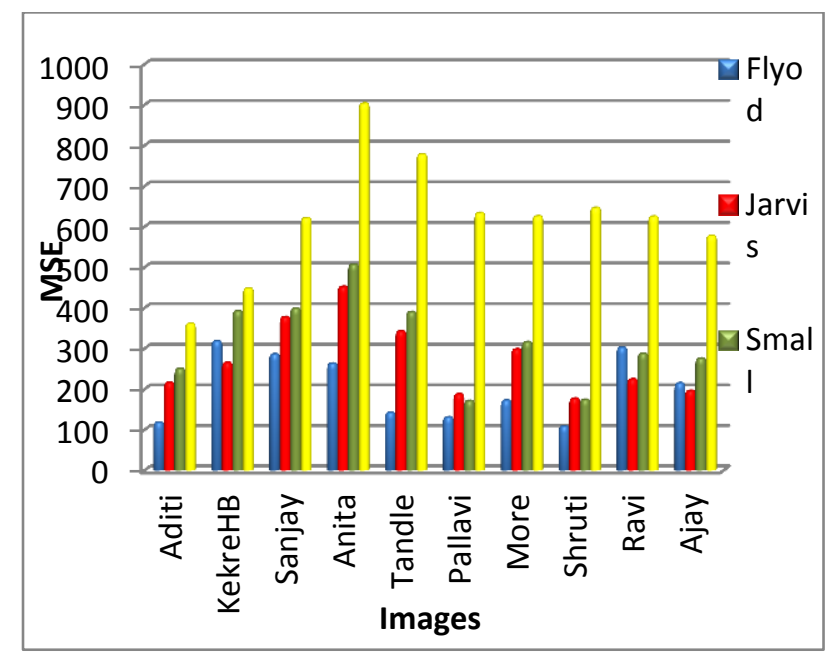

Figure 5. MSE between inverse and original images using different half tone operator and Wavelet Transorm at L1 
TABLE II. SSIM- BETWEEN INVERSE AND ORIGINAL IMAGE USING DIFFERENT HALF TONE OPERATORS WAVELET TRANSFORM AT-L1

\begin{tabular}{|c|c|c|c|c|c|}
\hline S.N & Image & Flyod & Jarvis & Small & $\begin{array}{c}\text { South- } \\
\text { East }\end{array}$ \\
\hline 1 & Aditi & 0.9911 & 0.9906 & 0.9911 & 0.9936 \\
\hline 2 & KekreHB & 0.966 & 0.9931 & 0.9798 & 0.999 \\
\hline 3 & Sanjay & 0.9957 & 0.9964 & 0.9968 & 0.9982 \\
\hline 4 & Anita & 0.9893 & 0.9909 & 0.9909 & 0.9939 \\
\hline 5 & Tandle & 0.9841 & 0.983 & 0.9842 & 0.9872 \\
\hline 6 & Pallavi & 0.998 & 0.9995 & 0.9996 & 1 \\
\hline 7 & More & 0.9936 & 0.9929 & 0.9936 & 0.9955 \\
\hline 8 & Shruti & 0.9958 & 0.9975 & 0.9978 & 0.9996 \\
\hline 9 & Ravi & 0.9821 & 0.9975 & 0.9989 & 0.9992 \\
\hline 10 & Ajay & 0.9769 & 0.9948 & 0.9946 & 0.9969 \\
\hline & Average & 0.98726 & 0.99362 & 0.99273 & 0.99631 \\
\hline
\end{tabular}

TABLE III. MSE- BetweEN INVERSE AND ORIGINAL IMAGE USING DIFFERENT HALF TONE OPERATORS WAVELET TRANSFORM AT-L2

\begin{tabular}{|c|c|l|l|l|l|}
\hline S.N. & Image & Flyod & Jarvis & Small & $\begin{array}{l}\text { South- } \\
\text { East }\end{array}$ \\
\hline 1 & Aditi & 117.9284 & 215.8858 & 249.9898 & 360.688 \\
\hline 2 & KekreHB & 318.1064 & 264.8021 & 391.9745 & 447.651 \\
\hline 3 & Sanjay & 285.8108 & 377.4875 & 398.578 & 621.227 \\
\hline 4 & Anita & 263.2586 & 452.0141 & 506.7903 & 903.045 \\
\hline 5 & Tandle & 142.0714 & 342.3254 & 389.9147 & 777.652 \\
\hline 6 & Pallavi & 130.8618 & 187.4659 & 171.0308 & 633.804 \\
\hline 7 & More & 172.1183 & 297.991 & 316.0038 & 625.25 \\
\hline 8 & Shruti & 108.5584 & 177.0218 & 173.9202 & 646.386 \\
\hline 9 & Ravi & 302.4952 & 224.187 & 287.0564 & 625.001 \\
\hline 10 & Ajay & 214.7103 & 195.7814 & 275.4808 & 577.054 \\
\hline & Average & 205.592 & 273.4962 & 316.07393 & 621.776 \\
\hline
\end{tabular}

TABLE IV. SSIM- BETWEEN INVERSE AND ORIGINAL IMAGE USING DIFFERENT HALF TONE OPERATORS WAVELET TRANSFORM AT-L2

\begin{tabular}{|c|c|c|c|c|c|}
\hline S.N. & Image & Flyod & Jarvis & Small & $\begin{array}{c}\text { South- } \\
\text { East }\end{array}$ \\
\hline 1 & Aditi & 0.9911 & 0.9906 & 0.9911 & 0.9937 \\
\hline 2 & KekreHB & 0.966 & 0.9931 & 0.9798 & 0.999 \\
\hline 3 & Sanjay & 0.9957 & 0.9964 & 0.9968 & 0.9982 \\
\hline 4 & Anita & 0.9893 & 0.9909 & 0.9909 & 0.9939 \\
\hline 5 & Tandle & 0.9841 & 0.983 & 0.9842 & 0.9872 \\
\hline 6 & Pallavi & 0.998 & 0.9995 & 0.9996 & 1 \\
\hline 7 & More & 0.9936 & 0.9929 & 0.9936 & 0.9955 \\
\hline 8 & Shruti & 0.9958 & 0.9975 & 0.9978 & 0.9996 \\
\hline 9 & Ravi & 0.9821 & 0.9975 & 0.9989 & 0.9992 \\
\hline 10 & Ajay & 0.9769 & 0.9948 & 0.9946 & 0.9969 \\
\hline & Average & 0.98726 & 0.99362 & 0.99273 & 0.99632 \\
\hline
\end{tabular}

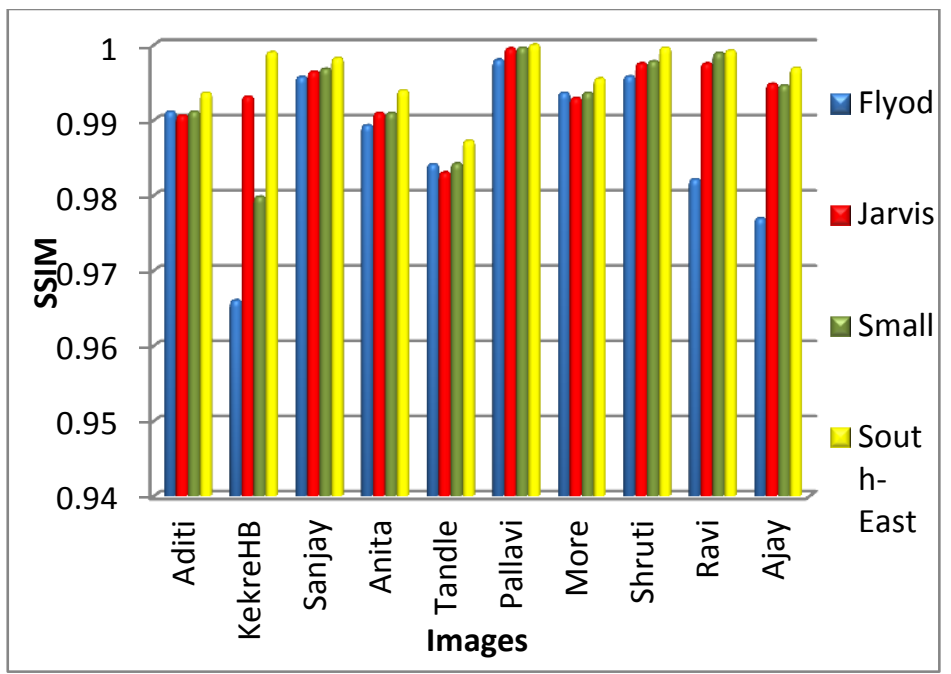

Figure 6. SSIM between inverse and original images using different half tone operator and Wavelet Transorm at L1

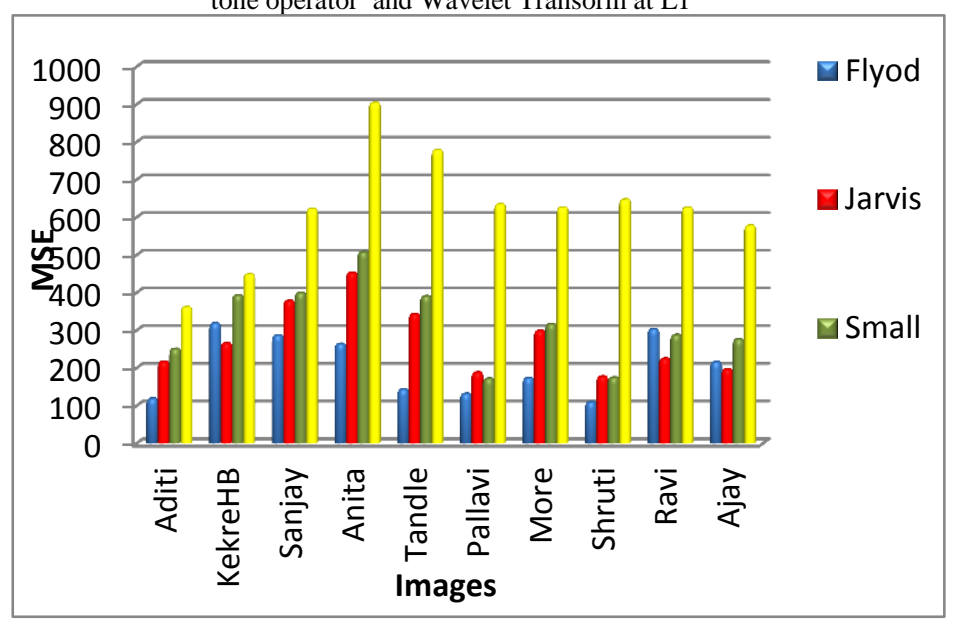

Figure 7. MSE between inverse and original images using different half tone operator and Wavelet Transorm at L2

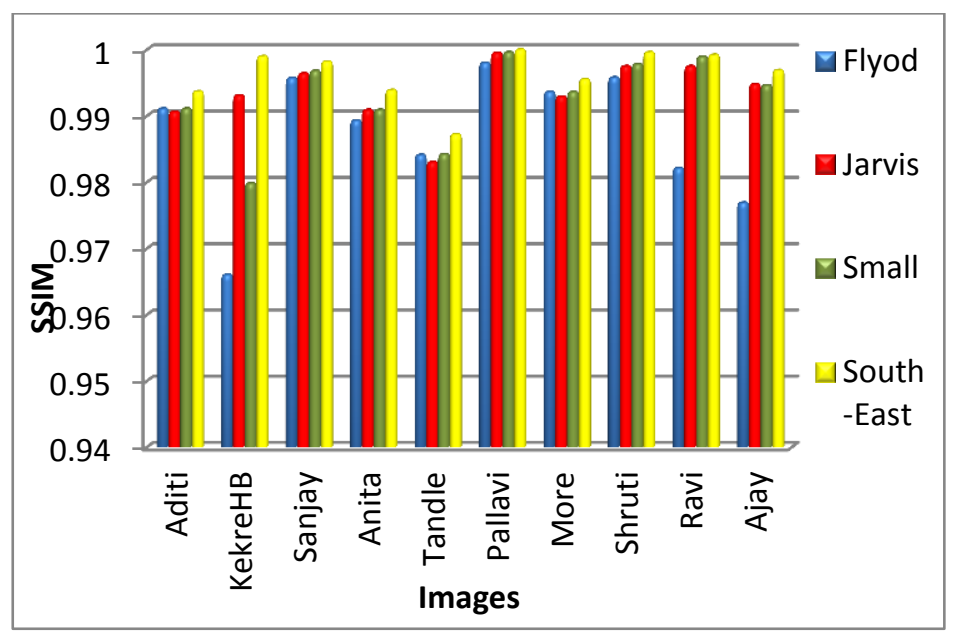

Figure 8. SSIM between inverse and original images using different half tone operator and Wavelet Transorm at L2 
TABLE V. MSE- BETWEEN INVERSE AND ORIGINAL IMAGE USING DIFFERENT HALF TONE OPERATORS WAVELET TRANSFORM AT-L3

\begin{tabular}{|c|c|l|l|l|l|}
\hline S.N. & Image & Flyod & Jarvis & Small & $\begin{array}{l}\text { South- } \\
\text { East }\end{array}$ \\
\hline 1 & Aditi & 134.267 & 220.2996 & 227.7553 & 370.799 \\
\hline 2 & KekreHB & 368.0072 & 224.9916 & 403.7703 & 435.893 \\
\hline 3 & Sanjay & 312.8477 & 345.6988 & 330.1543 & 461.705 \\
\hline 4 & Anita & 203.2026 & 264.9968 & 302.8949 & 542.179 \\
\hline 5 & Tandle & 121.0674 & 228.9125 & 226.9721 & 412.069 \\
\hline 6 & Pallavi & 163.8037 & 187.3523 & 169.3533 & 381.113 \\
\hline 7 & More & 171.3309 & 257.8598 & 236.361 & 428.801 \\
\hline 8 & Shruti & 155.6485 & 194.6737 & 175.9346 & 375.641 \\
\hline 9 & Ravi & 194.6619 & 190.1707 & 207.5549 & 436.251 \\
\hline 10 & Ajay & 121.9036 & 184.7462 & 195.4543 & 420.552 \\
\hline & Average & 194.6741 & 229.9702 & 247.6205 & 426.5 \\
\hline
\end{tabular}

TABLE VI. SSIM- BETWEEN INVERSE AND ORIGINAL IMAGE USING DIFFERENT HALF TONE OPERATORS WAVELET TRANSFORM AT-L3

\begin{tabular}{|c|c|l|l|l|l|}
\hline S.N. & Image & Flyod & Jarvis & Small & $\begin{array}{l}\text { South- } \\
\text { East }\end{array}$ \\
\hline 1 & Aditi & & 0.9905 & 0.991 & 0.9935 \\
\hline 2 & KekreHB & 0.9583 & 0.9998 & 0.972 & 1 \\
\hline 3 & Sanjay & 0.9927 & 0.9964 & 0.9968 & 0.9982 \\
\hline 4 & Anita & 0.9873 & 0.9908 & 0.9868 & 0.9938 \\
\hline 5 & Tandle & 0.984 & 0.9831 & 0.9841 & 0.9873 \\
\hline 6 & Pallavi & 0.9968 & 0.9995 & 0.9996 & 1 \\
\hline 7 & More & 0.9935 & 0.9929 & 0.9935 & 0.9955 \\
\hline 8 & Shruti & 0.9909 & 0.9974 & 0.9978 & 0.9989 \\
\hline 9 & Ravi & 0.9879 & 0.9963 & 0.999 & 0.9995 \\
\hline 10 & Ajay & 0.988 & 0.9947 & 0.9917 & 0.9969 \\
\hline & Average & 0.9866 & 0.99414 & 0.99123 & 0.9964 \\
\hline
\end{tabular}

Image data can be compressed to the higher level of Wavelet Transform say 16 X16 and 8 X8, but the image reconstruction quality degrades a lot.

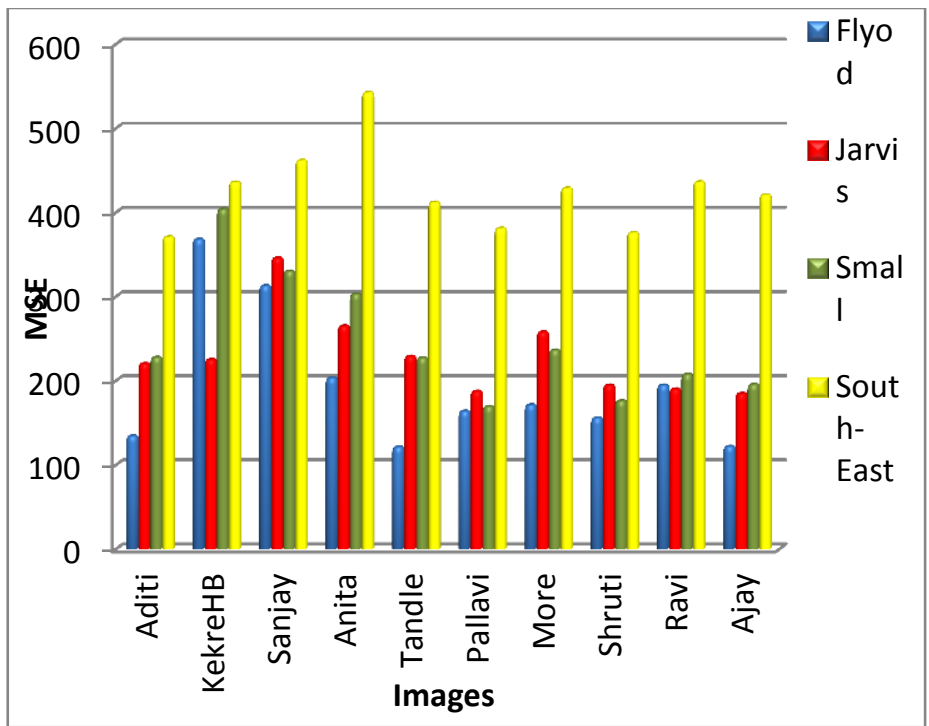

Figure 9. MSE between inverse and original images using different half tone operator and Wavelet Transorm at L3

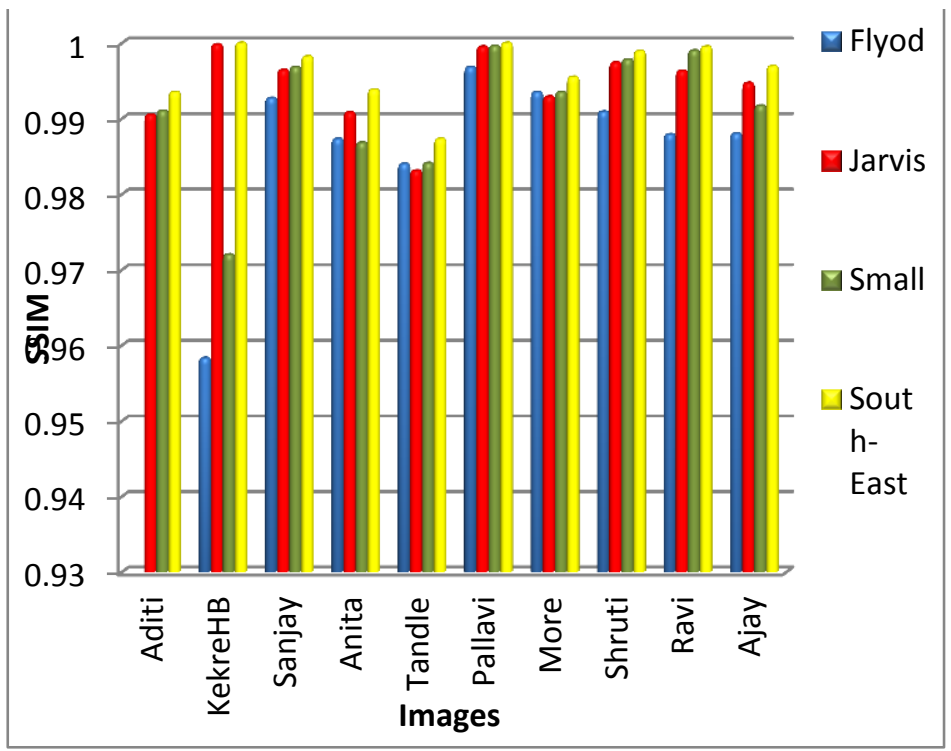

Figure 10. SSIM between inverse and original images using different half tone operator and Wavelet Transorm at L3 
TABLE VII. MSE- BETWEEN INVERSE AND ORIGINAL IMAGE USING DIFFERENT HALF TONE OPERATORS WAVELET TRANSFORM AT-L4

\begin{tabular}{|c|c|l|l|l|l|}
\hline & & Flyod & Jarvis & Small & $\begin{array}{l}\text { South- } \\
\text { East }\end{array}$ \\
\hline 1 & Aditi & 190.86 & 240.092 & 225.3853 & 345.85 \\
\hline 2 & KekreHB & 595.84 & 510.291 & 586.0695 & 360.28 \\
\hline 3 & Sanjay & 703.25 & 458.67 & 489.1887 & 541.14 \\
\hline 4 & Anita & 380 & 254.844 & 259.2035 & 378.81 \\
\hline 5 & Tandle & 231.56 & 204.578 & 197.7312 & 308.28 \\
\hline 6 & Pallavi & 232.66 & 199.918 & 184.2595 & 310.61 \\
\hline 7 & More & 275.28 & 243.013 & 241.0863 & 342.42 \\
\hline 8 & Shruti & 231.27 & 203.948 & 186.0357 & 300.9 \\
\hline 9 & Ravi & 978.47 & 235.499 & 480.6849 & 325.47 \\
\hline 10 & Ajay & 525.64 & 178.201 & 252.2813 & 311.26 \\
\hline & Average & 434.48 & 272.905 & 310.1926 & 352.5 \\
\hline
\end{tabular}

TABLE VIII. SSIM- BETWEEN INVERSE AND ORIGINAL IMAGE USING DIFFERENT HALF TONE OPERATORS WAVELET TRANSFORM AT-L4

\begin{tabular}{|c|l|l|l|l|l|}
\hline & & Flyod & Jarvis & Small & $\begin{array}{l}\text { South- } \\
\text { East }\end{array}$ \\
\hline 1 & Aditi & 0.991 & 0.9903 & 0.9908 & 0.9933 \\
\hline 2 & KekreHB & 0.9409 & 0.9553 & 0.9487 & 0.9842 \\
\hline 3 & Sanjay & 0.992 & 0.9962 & 0.9966 & 0.9981 \\
\hline 4 & Anita & 0.9759 & 0.9907 & 0.9847 & 0.9938 \\
\hline 5 & Tandle & 0.984 & 0.9831 & 0.984 & 0.9873 \\
\hline 6 & Pallavi & 0.9954 & 0.9994 & 0.9996 & 1 \\
\hline 7 & More & 0.9936 & 0.9929 & 0.9935 & 0.9955 \\
\hline 8 & Shruti & 0.9877 & 0.9974 & 0.9978 & 0.9989 \\
\hline 9 & Ravi & 0.9573 & 0.9941 & 0.9759 & 1 \\
\hline 10 & Ajay & 0.9605 & 0.9947 & 0.9825 & 0.9977 \\
\hline & Average & 0.97783 & 0.98941 & 0.98541 & 0.99488 \\
\hline
\end{tabular}

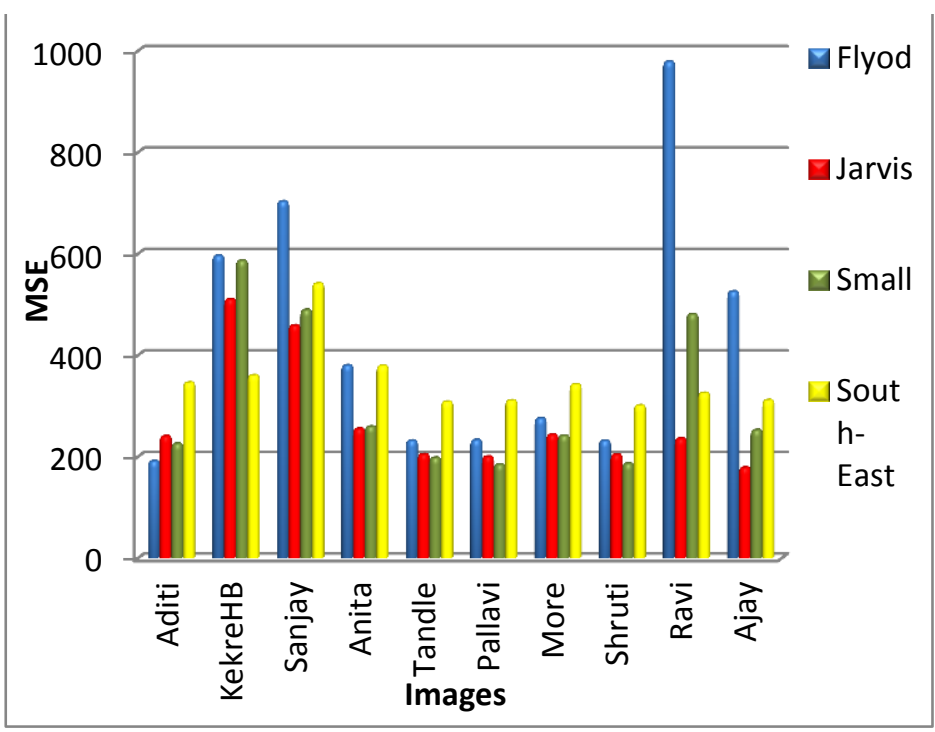

Figure 11. MSE between inverse and original images using different half tone operator and Wavelet Transorm at L4

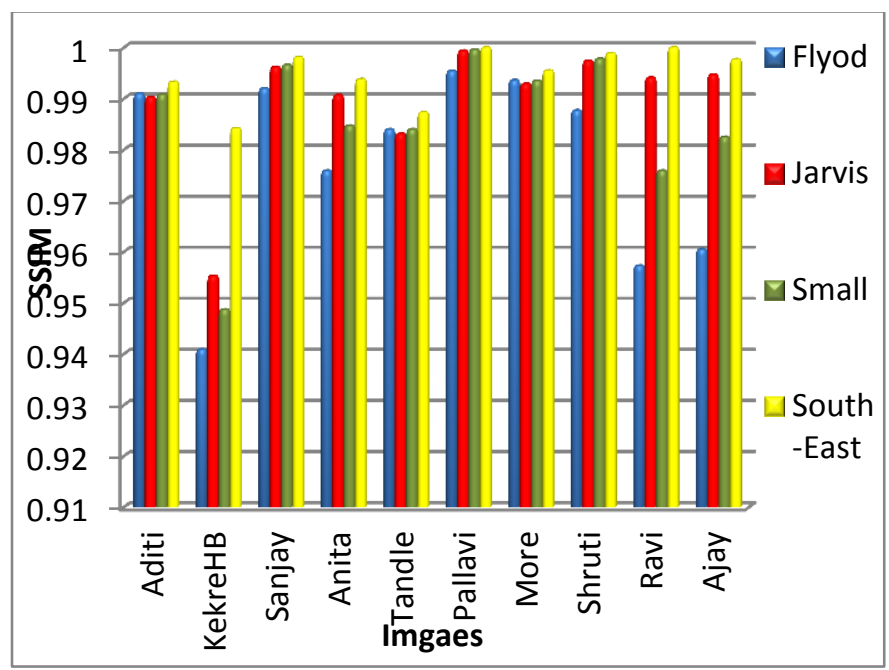

Figure 12. SSIM between inverse and original images using different half tone operator and Wavelet Transorm at L4 


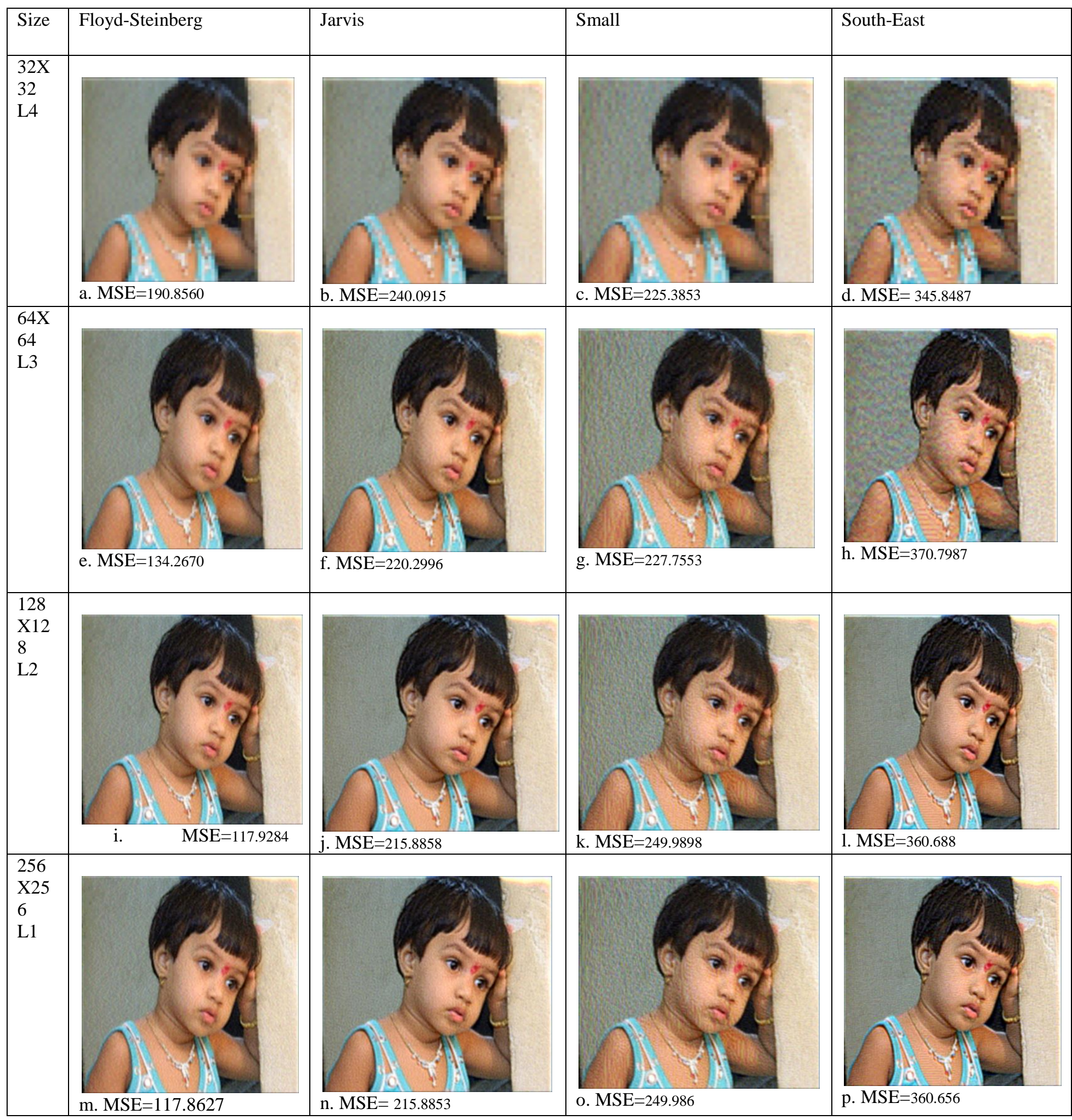

Figure 13. Reconstructed images using different half tone operators and Wavelet Transform at different levels from L1 to L4:
(1)
$\mathrm{CR}=32$ for $\mathrm{L} 1$,
(2) $\mathrm{CR}=128$ for
L2,
(3) $\mathrm{CR}=512$ for
L3,
(4)
$\mathrm{CR}=204$
for $\quad$ L4 


\section{CONCLUSION}

For low-bit rate video data transmission image data is compressed using combination of half tone and Wavelet Transform on ten different 512 by 512 bitmap images. Wavelet Transform is applied at different levels that converts image from 512 by 512 to 256 by 256 as level L1, 128 by 128 as L2, 64 by 64 as L3 and 32 by 32 as L4.

Below this level reconstructed image quality degrades. Future scope to this paper is to convert Wavelet Transform domain image into desired number of non-overlapping blocks. Calculate energy of all the blocks and can eliminate the some lowest energy blocks based on threshold. Elimination of such non-overlapping blocks will increase the CR. In real-time processing, proposed algorithm takes more processing time as compared to the frame rate that required for smooth video-conferencing. As well as to develop an algorithm to preserve the features of Low-High, High-Low and High-High components of Wavelet transform domain image and can be added to Low-Low frequency component of Wavelet transform.

\section{REFERENCES}

[1] S.Mallat,"ATheory of Multiresolution Signal Decomposition: The Wavelet Representation," IEEE Trans. Pattern Analysis and Machine Intelligence, vol.11,pp.674-693, 1989

[2] H.B.Kekre, T.K. Sarode Sudeep Thepade,'Inception of Hybrid Wavelet Tranform using Two Orthogonal Transforms and It's use for Image Compression", IJCSIS, vol.9, issue-6, pp.80-87.

[3] Hsieh-Wei Lee, King-Chu Hung, Tsung-Ching Wu, ChengTung Ku," A Modified Run-length Coding for the realization of Wavelet-based ECG Data Compression System", Journal of Next Generation Information Technology, Vol. 1. Number 1, May2010

[4] H.B.Kekre, Archna Athwale, Dipali Sadavarti, "Algorithm to Generate Wavelet Transform from an Orthogonal Transform", International Journal Of Image Processing (IJIP)", vol. 4, issue 4

[5] K Nagmani and AG Anath,'Image Compression Techniques for High Resolution Satellite Imageries using Classical Lifting Scheme", International Journal of Computer Applications(0975-8887), volume 15-No.13, February 2011

[6] H.B.Kekre, Archna Patankar and Dipali Koshti." Performance Comparision of simple Orthogonal Transform and Wavelet Tranforms for Image Stegnography", Inernation Journal of Computer Applications(0975-8887), volume 44-No.6, February 2012

[7] Seetharam Narasimhan, Massod Tabib," Neural Data Compression witn Wavelet Transform: A Vocabalry Based Approch", Procedings of 3rd International IEEE EMBS Conferenceon Neural engineering Kohal Coast, Hawaii USA, May2-5, 2007

[8] H.B.Kekre, T.K. Sarode ,Sudeep Thepade, Sonal Shroff,"Instigation of Orthogonal Wavelet Transforms using Walsh, Cosine, Hartley, Kekre Transforms and their use in Image Compression", (IJCSIS) International Journal of Computer Science and Information Security, Vol.XXX, No.XXX,2010
[9] H.B. Kekre, Tanuja K. Sarode, Sanjay R. Sange, Shachi Natu, and Prachi Natu , "Halftone Image Data Compression using Kekre's Fast Code Book Generation (KFCG) Algorithm for Vector Quantization", International Conference, ICTSM 2011, CCIS 145, pp. 34-42, 2011 (C) Springer-Verlag Berlin Heidelberg 2011, ICTSM 2011

[10] H. B. Kekre, Sanjay R. Sange, Gauri S. Sawant, and Ankit A. Lahoty International Conference, "Image Data Compression using Halftone and Huffman Coding", ICTSM 2011, CCIS 145, pp. 221-226, 2011 (C) Springer-Verlag Berlin Heidelberg 2011

[11] H.B. Kekre, Tanuja K. Sarode, Sanjay R. Sange, Pallavi Halankar,"New Half tone Operators for High Data Compression in Video- Conferencing", International Conference ICSCA 2012, on 9th and 10th June 2012, Singapore, published in International Proceedings of Computer Science and Information Technology (IPCSIT), volume 41, pg. 211-218, available online http://www.ipcsit.com/vol41/038-ICSCA2012-S3001.pdf

[12] H.B. Kekre, Tanuja K. Sarode, Sanjay R. Sange, Bhumika Raghwani, Merlin Vergis "Halftone Image Data Compression using KFCG Vector Quantization Algorithm for Video Conferencing", Journal of Signal and Image Processing, ISSN: 0976-8882 and E-ISSN: 09768890, Vol-2, Issue2, 2011, pp-42-49. Available online at http://www.bioinfo.in/contents.php?id=48

[13] H.B.Kekre, Sanjay R.Sange, "Restoration of Color Halftone image by using Fast Inverse Half toning Algorithm" International Conference on "Advances in Recent Technologies in Communication and Computing, (ARTCom 2009)" to be held on 27-28 October 2009 at Kottayam, Kerla, organized by ACEEE, Los Alamitos, California (U.S). 978-0-7695-3845-7/09

[14] H.B.Kekre, M.U.Kharat, Sanjay R. Sange , "Image data compression using new Halftoning operators and Run Length Encoding", International Conference on "Contours of Computing Technology, (THINKQUEST 2010)",pg-224 to pg-230 to be held on 13th-14th March 2010

\section{AUTHORS PROFILE}

Dr. H. B. Kekre B.E. (Hons.) in Telecomm. Engg. in 1958, M.Tech from IIT Bombay in 1960, M.S. Engg. from University of Ottawa in 1965 and Ph.D. from IIT Bombay in 1970. He is currently Senior Professor working with MPSTME, NMIMS, Mumbai INDIA. He has guided 17 Ph.D.s, 150 M.E./M.Tech Projects and several B.E./B.Tech Projects. His areas of interest are Digital Signal processing, Image Processing and Computer Networks. He has more than 400 papers in National/International Conferences/Journals to his credit. Recently his 12 students have received best paper awards. Seven of his students have been awarded $\mathrm{Ph}$. D. of NMIMS. Currently he is guiding ten $\mathrm{Ph} . \mathrm{D}$. students. He is member of ISTE and IETE.

Dr. Tanuja K. Sarode has received M.E.(Computer Engineering) from Mumbai University in 2004, Ph.D. from MPSTME SVKM's NMIMS, Mumbai, INDIA. She has more than 11 years of experience in teaching. She is currently working as Assistant Professor in Dept. of Computer Engineering at TSEC, Mumbai. She is member of IAENG and IACSIT. Her areas of interest are Image Processing, Signal Processing and Computer Graphics. She has more than 100 papers in National/International Conferences/journal to her credit.

Sanjay Ramkrishna Sange has received M.E. (Computer Engineering) from Mumbai University in $2008 . \mathrm{He}$ is the member of ISTE. He is pursuing his PhD. from NMIMS, Mumbai. $\mathrm{He}$ has presented/published 15 papers in National, International Conference/Journal. For one paper he has got "Best Paper" award in 2010. 